\title{
Serendipitous results stem from leukaemia study
}

A five-year research programme carried out with funding from the UK nuclear industry has failed to uncover any mechanism by which low-level ionizing radiation could cause childhood leukaemia. The research, however, uncovered cellular effects that may be significant in cancer treatment. It also showed that susceptibility to radiation damage in the cells of healthy individuals is an indicator of a genetic predisposition to cancer.

The UK nuclear industry set up the $£ 3$ million (US\$4.8 million) programme in a bid to obtain a definitive answer to the question of whether discharges from its nuclear plants are responsible for clusters of childhood leukaemia found nearby, such as that observed in Seascale, Cumbria, a village located two miles south of British Nuclear Fuels' Sellafield plant.

The research programme involved 40 projects and was directed by the United Kingdom Coordinating Committee on Cancer Research, bringing together seven cancer charities with the government.

The coordinating committee is also overseeing a parallel epidemiological study of childhood cancer being undertaken in Britain, which is expected to report its findings in three years time. Prompted by the same concerns about the effects of discharges from its plants, the nuclear industry is providing $£ 6$ million (US\$9.5 million) for this work.

Both the nuclear industry and the researchers involved have been keen to stress the impartiality of the research. At a meeting held in London in May to summarize the research findings, Dame Margaret Turner-Warwick, chair of the coordinating committee, stressed that decisions concerning the direction of the research programme were made independently of its nuclear industry sponsors. "Industry representatives have had no hand in deciding what projects should be funded, nor have they had any role in deciding what information should be published," Turner-Warwick said.

The stated aim of the programme was "to ascertain whether, in the context of exposure to ionizing radiation, there exists some special sensitivity or hitherto undiscovered mechanism that could give rise to a higher incidence of cancers (especially childhood leukaemias) than would be expected on current risk estimates."

Ged Adams, director of the MRC's Radiobiology Unit in Chilton, Oxfordshire, and one of the programme's supervisors, said that the research produced no such evidence, but that it nevertheless turned up "some exciting and unexpected findings." Adams singled out three areas because of their potential importance in cancer treatment: the discovery of mechanisms that explain why acute lymphoblastic leukaemia (the most common form of childhood cancer) is often treatable; variations in individual sensitivity to the effects of radiation that might influence a patient's response to treatment; and radiationinduced transmission instability that can be passed on to daughter cells and results in chromosomal abnormalities.

Ionizing radiation passes through tissue forming highly structured tracks. A particular feature of alpha-emitting radionuclides (plutonium and radon) is that all of the radiation is concentrated into a small

\section{"It follows that if a single}

\section{track alpha particle causes}

\section{lymphoid cells to commit}

\section{suicide, the radiation can't}

\section{cause cancer."}

number of separate, densely ionizing tracks. The question of whether low doses might induce cancer centres on an assessment of whether a single track damages a target cell.

The first of these areas of interest was uncovered by Mel Greaves, of the Leukaemia Research Fund Centre in London, who studied the radiation response of lymphoid cells (the main cell type involved in childhood leukaemia). The minimum possible dose of alpha radiation from plutonium (a single particle) resulted in cell death by apoptosis. Graves said "It follows that if a single track alpha particle causes lymphoid cells to commit suicide [undergo apoptosis], the [alpha] radiation can't cause cancer." Another inference is that the remarkable success in treating childhood leukaemia (especially acute lymphoblastic leukaemia) with cytotoxic drugs occurs because the cells involved are uniquely programmed to die.

Furthermore, Greaves has also shown that when genes that are associated with untreatable forms of leukaemia, that is
$B C L-2$ in follicular lymphoma, and $B C R-A B L$ and $p 53$ in subtypes of acute lymphoblastic leukaemia, are inserted into normal lymphoid precursor cells, this ultrasensitivity to radiation and drugs is blocked and the cells continue to divide. Greaves draws three conclusions from this:

- the $B C L-2, B C R-A B L$ and $p 53$ mutations responsible for untreatable forms of leukaemia somehow block apoptosis, which is required for the treatment to work;

- although apoptosis normally protects lymphoid cells from radiationinduced leukaemia by their dominant cell death response, they might be quite sensitive if - before exposure - they had already acquired a mutation that blocked apoptosis;

- as leukaemic cells (and possibly other cancer cells) carrying the $B C L-2, B C R-A B L$ and p53 mutations are more resistant to therapy, treatment that fails to kill them outright might cause further DNA damage and accelerate progression of the disease.

Work by David Scott at the Patterson Institute for Cancer Research at the Christie Hospital in Manchester also has implications for cancer treatment. Scott's research showed that the sensitivity of cells to radiation can be used as an indicator of an individual's predisposition to cancer and of their response to radiotherapy.

By irradiating peripheral blood lymphocytes and looking for signs of radiation damage, Scott showed that it was possible to predict a patient's response to radiotherapy. Studies on a few women with breast cancer who suffered unacceptable levels of tissue damage following radiotherapy showed that the radiation sensitivity of their lymphocytes was at the upper end of sensitivity for breast cancer patients in general. Scott now wants to develop the assay to identify these unusually sensitive patients, before treatment, so that more appropriate doses of radiation can be calculated. Alternatively, it may also be possible to increase doses of radiation for other women, improving their chances of cure.

Andy Slovak, a spokesperson for British Nuclear Fuels, said it was "cheerfully disconcerting it [the research] has come out the way it has." Indeed, the nuclear industry is so pleased with the relationship it has built up with the coordinating committee that it is now discussing further studies. NuALA MORAN London 